\title{
CORRELATION BETWEEN THE ENVIRONMENTAL KNOWLEDGE, ENVIRONMENTAL ATTITUDE, AND BEHAVIORAL INTENTION OF TOURISTS FOR ECOTOURISM IN CHINA
}

\author{
ZHENG, Q. J. ${ }^{1}-\mathrm{XU}$, A. X. ${ }^{1 *}-\mathrm{KONG}, \mathrm{D} . \mathrm{Y}^{2}{ }^{2}-\mathrm{DENG}, \mathrm{H} . \mathrm{P}^{1}{ }^{1}-\mathrm{LIN}, \mathrm{Q} . \mathrm{Q}^{1}$ \\ ${ }^{1}$ Ecological Civilization Center, Fujian Agriculture and Forestry University \\ No.15 Shangxiadian Road, Cangshan District, Fuzhou, Fujian 350002, China \\ ${ }^{2}$ Fujian Jiangxia University \\ No.2 Xiyuangong Road, University Town, Fuzhou, Fujian 350108, China \\ *Corresponding author \\ e-mail:872796767@qq.com
}

(Received $16^{\text {th }}$ Jun 2017; accepted $5^{\text {th }}$ Oct 2017)

\begin{abstract}
Due to the popularity of recreation and entertainment activities, the concept of ecotourism is getting popular in recent years. The research targets in this study include tourists to the Wuyi Mountain Duanyuan Ecological Tourism Zone, China. The convenience sampling approach is used in this study and a total of 500 questionnaire copies are dispatched. There are 372 valid questionnaire copies returned and the rate of response is $74 \%$. The results of this study indicate that 1.there is a positive correlation between the environmental knowledge and the environmental attitude, 2.there is a positive correlation between the environmental attitude and the environmental behavior, and 3.there is a positive correlation between the environmental knowledge and the environmental behavior. Finally, recommendations are proposed based on the research results and expected to be beneficial for culturing common people's environmental literacy, correct environmental attitude, environmental and ecological caring, and fulfillment of environmental behaviors.
\end{abstract}

Keywords: consumer movement, eco-management movement, environmental value, ecology, environmental belief

\section{Introduction}

Since the industrial revolution in the eighteenth century, with the prosperity of economy, technological advances, and the endless extraction of resources, people have consumed a vast amount of natural resources and further damaged the natural environment. The generation of more contaminations in air, water, and soil therefore leads to the accelerate extinction of species and the imbalance of the ecosystem. In recent years, with the fast development of economy, people are getting wealthier and the level of living standard is enhanced. However, various types of pollution are generated in succession. In recent years, the environmental problems are getting worse. Due to the popularity of the concept of recreation and entertainments and because of abundant humanism ancient monuments, eco-environmental planning and recreational facilities in the country, there are always heavy traffic and crowds of tourists during holidays. Although this phenomenon has activated the tourism industry, the large amount of garbage and air pollution also results in hassles. The motivation of this study is to understand tourists' environmental knowledge, environmental attitude, and environmental behavior. Nowadays, the environmental protection problems around the globe include greenhouse effect, acid rain, water resource depletion, garbage pollution, air pollution, and wildlife 
reduction. The ecosystem has been damaged and this leads to ecological imbalance and the deterioration of the living environment as well as the direct influence on people's lifeblood of sustainable survival. Moreover, with the fast expansion of human activities, the resources on the Earth have been consumed rapidly and an excessive amount of pollutions and wastes have been generated. The resources on the Earth are limited and we have to value the sustainable development of the environment and avoid excessive developments and utilizations which lead to the deterioration of our living environment. The important and inherent path to changes is to enhance our knowledge via education and change every individual's attitude and behavior. This allows every person to own abundant environmental knowledge, adequate environmental attitude, and correct environmental behaviors. Therefore, we appreciate the emphasis by the international society on the environmental knowledge and expect to change every individual's attitude and behavior via education. This is because the eventual goal of the environment education is to improve people's environmental behaviors. The best timing for improving behaviors is to culture them from the childhood. During this stage, people have a better learning capability with a greater level of flexibility. Via the process of conceptual perceptions and the clarification of value during this stage, people can learn to establish the environmental awareness and sensitivity, environmental concept and knowledge, environmental value and attitude, environmental action skills, and environmental action experiences. It is therefore necessary and urgent to culture people's environmental literacy, correct the environmental attitude, environmental and ecological caring, and the fulfillment of environmental behaviors.

\section{Literature review}

\section{The study of the correlation between environmental knowledge and environmental attitude}

Van Birgelen et al. (2011) indicated that a significant correlation existed between a schoolchild's environmental knowledge of oceans and he/her attitude. Lu and Shon (2012) studied high school students who took ten days of environmental science education and discovered that the students had a higher level of environmental knowledge and held a more optimistic and positive attitude toward the environment. The studies of other scholars (Lee, 2011a) also indicated that, after a student taking the course of training of the environment for four to eight weeks, there was a positive correlation between the environmental knowledge and his/her environmental attitude. It is obvious that the education behavior is positively beneficial for enhancing environmental knowledge and the environmental attitude. The study by Van Birgelen et al. (2011) indicated that there was a significantly positive correlation between a high school teacher's environmental sensitivity and the environmental knowledge. For the correlation between perception and the affective domain, Kim et al. (2014) proposed that an elementary school teacher's environmental knowledge was positively correlated to the perception of environmental problems in Taiwan, environmental awareness, cosmic belief, and social values. Araghi et al. (2014) selected students of a public vocational training organization as the research targets and discovered that there was a significant correlation between a student's environmental knowledge and his/her environmental attitude. As a result, this study proposes several hypotheses as follows.

Hypothesis 1: The environmental knowledge is positively correlated to the environmental attitude. 


\section{The study of the correlation between environmental attitude and environmental behavior}

Scheelhaase et al. (2010) also indicated that factors of (1) Environmental sensitivity, (2) Personal control belief, (3) Group control belief, and (4) Attitude toward pollution had a significantly positively correlation to environmental behavior. Abdollahzadehgan et al. (2013) used garbage recycling as an example for investigating the correlation between environmental behavior and various types of factors. In his study, the environmental attitude was found to be independent of these factors. In another word, people who had positive and optimistic environmental attitude would not necessarily fulfill the behavior of garbage recycling actively. Sultan (2013) conducted an investigation on 1225 nature and environment education centers and indicated that the development of an individual's attitude was beneficial for developing responsible behaviors toward the environment. Davison et al. (2014) carried out the study of factors relevant to responsible environmental behaviors. They also found that an individual with a more positive and optimistic attitude toward environmental issues could contribute to his/her responsible behaviors. Chen (2013) also conducted an investigation of environmental attitudes and behaviors on Taipei City and Kaohsiung City citizens. It was found that the degree of correlation between environmental attitude and behavior was low to moderate. Vlahakis et al. (2013) selected six-grade students of elementary schools in Taoyuan County as the research targets and found that the environmental attitude was correlated to the choice of environmental action strategies. Zsóka et al. (2013) selected students of the National Taiwan University as the targets and revealed the research results that these students presented a significant correlation and consistency between their overall attitude toward eco-friendly and their real eco-friendly behaviors that had been observed. As a result, another hypothesis is proposed in this study as follows.

Hypothesis 2: Environmental attitude is positively correlated to the environmental behavior.

\section{The study of the correlation between environmental knowledge and environmental behavior}

Van Der Linden (2014) conducted a meta-analysis of studies relevant to the aspect of environmental behaviors since 1971. It was found that the environmental behavior was positively correlated to an individual's degree of understanding for environmental problems. Shabnam (2013) also proposed that there were significantly positive correlations between the knowledge of environmental action strategies and environmental behaviors. In other words, the knowledge of environmental action strategy had a significant influence on environmental behaviors. The results obtained by Ziegler et al. (2012) from telephone surveys also indicated that the people with more sufficient preservation knowledge tended to undertake more tasks such as garbage recycling and were willing to devote themselves to environment protection tasks. Enfield and Mathew (2012) used garbage recycling as an example for investigating the correlation between environmental behaviors and various types of factors. They proposed that there was a close correlation between a frequent supplement of information and guidance and the fulfillment of a behavior. The study by Ko and Dennis (2011) indicated that environmental knowledge was correlated to environmental action. As a result, another hypothesis is proposed in this study as follows. 
Hypothesis 3: Environmental knowledge is positively correlated to environmental behavior.

\section{Environmental knowledge}

Environmental knowledge refers to an individual's understanding of the things and objects in the environment (Lee, 2011a) and the scope of its coverage is very extensive. Davison et al. (2014) classified the environment education into thirteen categories which included environmental management, environmental management technique, environmental problem, geo-ecology, economics, social and cultural environment, adaptation and evolution, natural resource, culture, politics, family, individual, and mentality. Any knowledge relevant to this territory was included in the scope of the environmental knowledge. Kim et al. (2014) proposed eleven principal ideas of the teaching materials for environmental education, including the general concepts, air pollution, noise pollution, urban problem, balance of nature, forest and wood preservation, human resource preservation, land resource maintenance, wise utilization of minerals, hydraulic resource preservation, and wildlife preservation. Araghi et al. (2014) proposed that the environmental knowledge was an interdisciplinary subject that was a type of knowledge derived from the nature, social science, and anthropology. It sometimes was also related to ethics including value and the assignment of authority. The level of its coverage was very extensive and people's basic necessities of life could not sustain without the environment. For this reason, any knowledge that is relevant to people's life and the environment could be called the environmental knowledge (Mantzicopoulos and Patrick, 2011).

According to the study by Chang (2011), the constituent elements for evaluating the environmental knowledge can be classified as follows.

- Ecology: Environmental conservation and the diversity of creatures.

- Environmental science: Air pollution and prevention, water resource preservation and water pollution prevention, soil contamination prevention and soil and water conservation, noise pollution and prevention, garbage and business wastes pollution prevention, environmental sanitation and food hygiene, and sustainable energy.

- Environmental issue: Environmental issue, nuclear power generation and radiation safety, population hygiene, air pollution and prevention, water resource preservation and water pollution prevention, and garbage and business wastes pollution prevention.

\section{Environmental attitude}

Lian et al. (2014) proposed that an attitude was an individual's inner intention toward a target object and was the origin and preparation for a behavior. An attitude is a type of complex psychological process which includes the tendency of perception, emotion, and behaviors and is provided with enduring and consistent characteristics. Enfield and Mathew (2012) proposed that the environmental attitude indicated the combination of the beliefs toward the special conditions of the environment, the entire environment, and the people or objects directly relevant to the environment. These combinations comprised an overall assessment which could be assent or objection, and like or aversion. When an individual is provided with this emotion, he/she will generate a strong sense of caring for the environment, actively participate in environmental 
protection, and generate the motivation of improvements (Mitchener and Jackson, 2012). Abdollahzadehgan et al. (2013) proposed that an environmental attitude was an individual's level of dedication and support for the things and objects in the environment. Sultan (2013) proposed that an attitude was a type of enduring and consistent tendency of an individual for people, things, and the surrounding world. It could be conjectured from explicit behaviors but its connotation was not limited to purely explicit behaviors. Ko and Dennis (2011) proposed that an environmental attitude meant a schoolchild's value for the overall environment and the opinion of people's duty and role for residing in the environment. Furthermore, depending on the integration of individual perceptions, they generated the emotional tendency to agree or disagree, like or dislike certain things or objects that were relevant to the environment. For example, these included the self-awareness of the duty for the environment or the degree of their concern for environmental problems. Van Birgelen et al. (2011) proposed that an environmental attitude meant an individual's opinion or tendency for the belief and value of environmental issues and whether they agreed with or opposed to and preferred or were averse to an action. An environmental attitude can therefore be delimited as an individual's characteristics that are formed in the long run. They will continuously be concerned with environmental issues and eventually take actions in environment protection. In this case, the environmental attitude includes the environmental value and the environmental belief (Van Birgelen et al., 2011). At the same time, it can also demonstrate an individual's opinion of the duty and role of human beings in the environment.

The environmental attitude in this study is combined with the environmental knowledge and the main purpose is to investigate the attitude held by the research targets for the environmental problems. Based on the study by Chen (2013), the environmental attitude is therefore classified into two constituent elements, including environmental value and environmental belief, so as to understand environmental attitude and tendency.

\section{Behavioral intention}

The individual behaviors studied in psychology indicate that individual activities can be observed or measured by instruments in a narrow sense of explanation. From a generalized definition, they include not only the explicit activities that can be directly observed or measured, but also the internal psychological processes that can be indirectly predicted. The internal psychological processes include the conscious process and unconsciousness process (British Airways, 2012). A behavior is a type of generalization term and its connotation includes all activities of an individual (Lee, 2011b). Alatawi et al. (2012) defined an environmental behavior as the behavior that was presented by an individual or group so as to resolve a certain environmental problem. In another word, it meant the path taken by an individual or a group to prevent or resolve environmental problems or issues (Chen et al., 2011). The most important key factor is whether an individual can actively participate in. An environmental behavior is namely the behavior presented by a person, an individual, or a group to resolve a certain environmental problem. After an environmental citizen is equipped with the environmental knowledge, environmental attitude, and environmental skills, he/she has to take actions and participate in resolving various types of environmental problems. The levels of participating in such type of actions may have different names such as environmental action, citizen participation, or responsible environmental 
behaviors. However, all of them emphasize the importance of people's active participation and actions to resolve or prevent environmental problems (Hadzigeorgiou et al., 2011). In this study, the behavioral intention is classified into two constituent elements, including eco-management movement and consumer movement proposed by Joe et al. (2013).

\section{Methodology}

\section{Research targets and sampled data}

Tourists to the Wuyi Mountain Duanyuan Ecological Tourism Zone, China, are selected in this study as the research targets. The convenience sampling approach is used in this study. A total of 500 questionnaire copies are dispatched. The number of valid questionnaire copies returned is 372 and the rate of response for this questionnaire is 74\%. After questionnaire copies are returned, the statistical software SPSS is used for carrying out data analysis. Statistical methods including the factor analysis and reliability analysis, regression analysis, and structural equation models are used for examining each of the hypotheses. The Wuyi Mountain Duanyuan Ecological Tourism Zone is in Fujian, China. The most distinguishing feature of the Wuyi Mountain Duanyuan Ecological Tourism Zone is its coastline. It has been the most favorite tourist attraction for Chinese people. Due to millions of years of crust motions, the lands and the ocean have been integrated into each other and this brings up the unique landscapes in this area. Chen et al. (2011) stated the world under the sea is even more fabulous and colorful. Various types of fish species and colorful corals have become the representing distinguishing feature. From the ecological aspect, the tropical region climate has cultivated vital tropical and seashore plants. There are numerous migratory birds transiting every year in autumn and winter and this makes it become a notable birdwatching attraction (Lian et al., 2014). In addition, several prehistoric monuments and cultural heritages of the indigenous people are also discovered in this area and these have become the invaluable humanism assets.

\section{Analysis method}

The regression analysis is used in this study for understanding the correlation between environmental knowledge and environmental attitude. Furthermore, the analysis of structural equation models is used for understanding the correlation between the tourists' environmental attitude and their behavioral intention.

\section{Results}

\section{Reliability and validity analysis}

After the factor analysis in this study, three factors are extracted from the environmental knowledge. The first factor is "ecology" (eigenvalue $=2.671, \alpha=0.83$ ). The second factor is "environmental science" (eigenvalue $=2.247, \alpha=0.80$ ). The third factor is "environmental issue" (eigenvalue $=1.951, \alpha=0.82$ ). The cumulative explained common variance of these three factors reaches $79.524 \%$.

After the factor analysis in this study, two factors are extracted from environmental attitude. The first factor is "environmental value" (eigenvalue $=3.162, \alpha=0.88$ ). The second factor is "environmental belief" (eigenvalue $=2.976, \alpha=0.85$ ). The cumulative 
explained common variance of these two factors reaches $81.195 \%$.

After the factor analysis in this study, three factors are extracted from the behavioral intention. The first factor is "eco-management movement" (eigenvalue $=2.533, \alpha=0.86$ ). The second factor is "consumer movement" (eigenvalue $=1.884, \alpha=0.89$ ). The cumulative explained common variance of these two factors reaches $82.438 \%$.

\section{The analysis of the correlation between environmental knowledge and environmental attitude}

The analysis results are shown in Table 1. After verifying Hypothesis H1, the analysis results reveal that, ecology $(\mathrm{t}=2.134 * *)$, environmental science $(\mathrm{t}=1.734 *)$, and environmental issue ( $\mathrm{t}=2.238 * *)$ have a significant influence on environmental value. On the other hand, ecology $(\mathrm{t}=1.942 *)$, environmental science $(\mathrm{t}=1.856 *)$, and environmental issue $(\mathrm{t}=1.914 *)$ have a significant influence on environmental belief. Hypothesis $\mathrm{H} 1$ is therefore valid.

Table 1. Analysis of the constituent elements of environmental knowledge versus environmental attitude

\begin{tabular}{c|c|c|c|c}
\hline $\begin{array}{c}\text { Dependent variable } \\
\rightarrow\end{array}$ & \multicolumn{3}{|c}{ Environmental attitude } \\
\hline Independent variable $\downarrow$ & \multicolumn{2}{|c|}{ Environmental value } & \multicolumn{2}{c}{ Environmental belief } \\
\hline $\begin{array}{c}\text { Environmental } \\
\text { knowledge }\end{array}$ & Beta & $\mathrm{t}$ & Beta & $\mathrm{t}$ \\
Ecology & 0.202 & $2.134 * *$ & 0.188 & $1.942 *$ \\
Environmental science & 0.168 & $1.734 *$ & 0.175 & $1.856 *$ \\
Environmental issue & 0.213 & $2.238 * *$ & 0.182 & $1.914 *$ \\
\hline F Value & \multicolumn{2}{|c|}{24.528} & \multicolumn{2}{|c}{37.462} \\
Significance & \multicolumn{2}{|c|}{$0.000 * * *$} & \multicolumn{2}{c}{$0.000 * * *$} \\
R2 & \multicolumn{2}{|c}{0.256} & \multicolumn{2}{c}{0.334} \\
R2 after adjustment & \multicolumn{2}{|c|}{0.022} & \\
\hline
\end{tabular}

Remark: * p Value $<0.05, * * \mathrm{p}$ Value $<0.01, * * * \mathrm{p}$ Value $<0.001$

Data Sources: Summarized by this study.

The study of the correlation between environmental knowledge and behavioral intention and environmental attitude

(1) The analysis of the correlation between environmental knowledge and behavioral intention

The analysis results are shown in Table 2. After verifying Hypothesis $\mathrm{H} 3$, the analysis results reveal that, ecology $(\mathrm{t}=2.216 * *)$, environmental science $(\mathrm{t}=1.857 *)$, and environmental issue $(\mathrm{t}=1.946 *)$ have a significant influence on the ecomanagement movement. On the other hand, ecology $(\mathrm{t}=2.361 * *)$, environmental science $(\mathrm{t}=1.762 *)$, and environmental issue $(\mathrm{t}=2.188 * *)$ have a significant influence on the consumer movement. Consequently, Hypothesis $\mathrm{H} 3$ is valid. 
(2) The analysis of the correlation between environmental attitude and behavioral intention

The analysis results are shown in Table 2. After verifying Hypothesis $\mathrm{H} 2$, the analysis results reveal that, environmental value $(\mathrm{t}=2.325 * *)$ and environmental belief $(\mathrm{t}=2.264$ **) have a significant influence on the eco-management movement. On the other hand, environmental value $(\mathrm{t}=2.463 * *)$ and environmental belief $(\mathrm{t}=2.587 * *)$ have a significant influence on consumer movement. Accordingly, Hypothesis $\mathrm{H} 2$ is valid.

Table 2. Analysis of the constituent elements of environmental knowledge versus environmental attitude

\begin{tabular}{|c|c|c|c|c|c|c|c|c|}
\hline Dependent & \multicolumn{8}{|c|}{ Behavioral intention } \\
\hline $\begin{array}{c}\text { Independent } \\
\text { variable } \downarrow\end{array}$ & \multicolumn{2}{|c|}{$\begin{array}{l}\text { Eco-management } \\
\text { movement }\end{array}$} & \multicolumn{2}{|c|}{$\begin{array}{l}\text { Consumer } \\
\text { movement }\end{array}$} & \multicolumn{2}{|c|}{$\begin{array}{c}\text { Eco- } \\
\text { management } \\
\text { movement }\end{array}$} & \multicolumn{2}{|c|}{$\begin{array}{l}\text { Consumer } \\
\text { movement }\end{array}$} \\
\hline $\begin{array}{c}\text { Environmental } \\
\text { knowledge }\end{array}$ & Beta & $\mathrm{t}$ & Beta & $\mathrm{t}$ & & & & \\
\hline Ecology & 0.211 & $2.216 * *$ & 0.223 & $2.361 * *$ & & & & \\
\hline $\begin{array}{l}\text { Environmental } \\
\text { science }\end{array}$ & 0.171 & $1.857 *$ & 0.163 & $1.762 *$ & & & & \\
\hline $\begin{array}{c}\text { Environmental } \\
\text { issue }\end{array}$ & 0.182 & $1.946 *$ & 0.206 & $2.188 * *$ & & & & \\
\hline $\begin{array}{l}\text { Environmental } \\
\text { attitude }\end{array}$ & & & & & & & & \\
\hline $\begin{array}{c}\text { Environmental } \\
\text { value }\end{array}$ & & & & & 0.221 & $2.325 * *$ & 0.237 & $2.463 * *$ \\
\hline $\begin{array}{c}\text { Environmental } \\
\text { belief }\end{array}$ & & & & & 0.214 & $2.264 * *$ & 0.241 & $2.587 * *$ \\
\hline F Value & \multicolumn{2}{|c|}{16.438} & \multicolumn{2}{|c|}{19.524} & \multicolumn{2}{|c|}{22.381} & \multicolumn{2}{|c|}{25.163} \\
\hline Significance & \multicolumn{2}{|c|}{$0.000 * * *$} & \multicolumn{2}{|c|}{$0.000 * * *$} & \multicolumn{2}{|c|}{$0.000 * * *$} & \multicolumn{2}{|c|}{$0.000 * * *$} \\
\hline $\mathrm{R} 2$ & \multicolumn{2}{|c|}{0.165} & \multicolumn{2}{|c|}{0.173} & \multicolumn{2}{|c|}{0.213} & \multicolumn{2}{|c|}{0.238} \\
\hline $\begin{array}{c}\text { R2 after } \\
\text { adjustment }\end{array}$ & \multicolumn{2}{|c|}{0.014} & \multicolumn{2}{|c|}{0.016} & \multicolumn{2}{|c|}{0.019} & \multicolumn{2}{|c|}{0.021} \\
\hline
\end{tabular}

Remark: * p Value $<0.05, * * \mathrm{p}$ Value $<0.01, * * * \mathrm{p}$ Value $<0.001$

Data Sources: Summarized by this study.

\section{LISREL model evaluation indicators}

The data obtained in this study are summarized in Table 3 and Table 4. The simple goodness-of-fit, internal goodness-of-fit, and global goodness-of-fit of this model are described respectively as follows.

The results of the full model analysis in Table 3 reveal that, from the simple goodness-of-fit aspect, the three constituent factors (ecology, environmental science, and environmental issue) of environmental knowledge reach the significant level $(t>1.96, p<0.05)$ in the explanation of environmental knowledge. The two constituent factors (environmental value and environmental belief) of environmental attitude reach 
the significant level $(\mathrm{t}>1.96, \mathrm{p}<0.05)$ in the explanation of the environmental attitude. The two constituent factors of behavioral intention reach the significant level $(t>1.96$, $\mathrm{p}<0.05)$ in the explanation of behavioral intention. It is known from this that the global model of this study is provided with good simple goodness-of-fit.

From the internal goodness-of-fit aspect, there is a positive significant correlation between environmental knowledge and environmental attitude $(0.843, \mathrm{p}<0.01)$. There is also a positively significant correlation between environmental attitude and behavioral intention (0.866, $\mathrm{p}<0.01)$. Environmental knowledge and behavioral intention $(0.873, \mathrm{p}$ $<0.01)$ also provide a positive significant correlation, representing that Hypotheses 1, 2, and 3 are all supported.

Table 3. Analysis results of the global linear structural model

\begin{tabular}{|c|c|c|c|c|}
\hline $\begin{array}{l}\text { Evaluation } \\
\text { items }\end{array}$ & \multicolumn{2}{|c|}{ Parameter / assessment criteria } & Results & t Value \\
\hline \multirow{7}{*}{$\begin{array}{c}\text { Simple } \\
\text { goodness-of-fit }\end{array}$} & \multirow{3}{*}{$\begin{array}{l}\text { Environmental } \\
\text { knowledge }\end{array}$} & Ecology & 0.716 & $8.52 * *$ \\
\hline & & $\begin{array}{l}\text { Environmental } \\
\text { science }\end{array}$ & 0.721 & $9.66 * *$ \\
\hline & & $\begin{array}{l}\text { Environmental } \\
\text { issue }\end{array}$ & 0.711 & $7.84 * *$ \\
\hline & \multirow{2}{*}{$\begin{array}{l}\text { Environmental } \\
\text { attitude }\end{array}$} & $\begin{array}{c}\text { Environmental } \\
\text { value }\end{array}$ & 0.753 & $10.62 * *$ \\
\hline & & & 0.762 & $11.85 * *$ \\
\hline & \multirow{2}{*}{ Behavioral intention } & $\begin{array}{l}\text { Eco-management } \\
\text { movement }\end{array}$ & 0.811 & $12.36 * *$ \\
\hline & & $\begin{array}{l}\text { Consumer } \\
\text { movement }\end{array}$ & 0.823 & $13.55 * *$ \\
\hline \multirow{3}{*}{$\begin{array}{c}\text { Internal } \\
\text { goodness-of-fit }\end{array}$} & \multirow{3}{*}{\multicolumn{2}{|c|}{$\begin{array}{c}\text { Environmental knowledge } \rightarrow \\
\text { environmental attitude } \\
\text { Environmental attitude } \rightarrow \text { behavioral } \\
\text { intention } \\
\text { Environmental knowledge } \rightarrow \text { behavioral } \\
\text { intention }\end{array}$}} & 0.843 & $33.46 * *$ \\
\hline & & & 0.866 & $38.72 * *$ \\
\hline & & & 0.873 & $43.15 * *$ \\
\hline $\begin{array}{c}\text { Global } \\
\text { goodness-of-fit }\end{array}$ & \multicolumn{2}{|c|}{$\begin{array}{c}\text { X2/Df } \\
\text { GFI } \\
\text { AGFI } \\
\text { RMR }\end{array}$} & \multicolumn{2}{|c|}{$\begin{array}{l}1.822 \\
0.973 \\
0.917 \\
0.004 \\
\end{array}$} \\
\hline
\end{tabular}

Remark: * p Value $<0.05, * * \mathrm{p}$ Value $<0.01, * * * \mathrm{p}$ Value $<0.001$

From the model's global goodness-of-fit aspect, the global model's goodness-of-fit value $\chi 2 / \mathrm{Df}$ is 1.822 , which is smaller than the criterion of 3 . The RMR value is 0.004 , which indicates the resulting criteria of $\chi 2 / \mathrm{DF}$ and RMR (Root mean square residual) are adequate. Moreover, since the chi-square value is very sensitive to the sample size, it is not adequate to directly use this for determining the suitable condition. However, the GFI (Goodness of fit index) value of the global model goodness-of-fit standard is 0.973 and the AGFI (Adjusted goodness of fit index) is 0.917 which are larger than the criteria of 0.9. (When the GFI, AGFI values are closer to 1, it indicates the model's goodnessof-fit is better.) As a result, this model is provided with a better goodness-of-fit indicator. 
Table 4. Verification of hypotheses

\begin{tabular}{c|c|c|c|c}
\hline $\begin{array}{c}\text { Research } \\
\text { hypotheses }\end{array}$ & Correlation & $\begin{array}{c}\text { Empirical } \\
\text { results }\end{array}$ & P Value & Result \\
\hline Hypothesis 1 & + & 0.843 & $\mathrm{P}<0.01$ & Valid \\
Hypothesis 2 & + & 0.866 & $\mathrm{P}<0.01$ & Valid \\
Hypothesis 3 & + & 0.873 & $\mathrm{P}<0.01$ & Valid \\
\hline
\end{tabular}

\section{Discussions}

The results of this study reveal that people with a higher score of environment knowledge present a more optimistic environmental attitude and vice versa. These two factors present a significantly positive correlation. People with more optimistic environmental attitudes present positive environmental behaviors and vice versa. These two factors present a significantly positive correlation. People with more abundant environment knowledge display more positive environmental behaviors and vice versa. These two factors present a significantly positive correlation. It is thus clear that environmental issues are an important topic that people in the 21th century have to face seriously. The relationship between people and the environment is getting worse. Unless people change their behaviors and show a respectful attitude towards the environment, the end of the world and people can be expected. To resolve the environmental problems, it is necessary to trigger people's environmental awareness and therefore this highlights the importance of the education of environmental knowledge. While the government is developing the tourism industry, it is recommended that the relevant environmental protection organizations can plan their strategies for the abovementioned pollutions. The required manpower and expenditures should be included during budget planning so as to present landscapes and the living environment with high quality to tourists and citizens.

\section{Conclusions}

Based on the above research results obtained in this study, some conclusions are proposed as follows for future researches and practicers.

1. Organizing eco-friendly activities: It is recommended to organize eco-friendly activities such as beach cleanup, mountain cleanup, resource recycling, etc. On one hand, these activities enhance people's environmental value. On the other hand, via firsthand experiences, people can be cultured to have more optimistic environmental attitudes and responsible environmental behaviors.

2. Application of selection tools: People need to keep enriching their environmental knowledge. It is recommended to well use the Internet, newspaper and magazine media, advocating DVDs, and posters. The resources provided by the local government's environmental protection bureau can also be used for enriching people's knowledge and capability obtained from the environmental education. This can further affect the acquisition of people's environment knowledge and it is advised to indeed fulfill environmental education into the activities of daily living. 
3. Supplying related information and training: It is recommended to fulfill and integrate the environment education knowledge into school courses. Depending on the different grades of schoolchildren, different breadth and depth should be available. During the activities of daily living, it is necessary to continuously emphasize the importance of the environmental attitudes toward the improvement of our environment, such as turning off lights when leaving and using both sides of paper and then have it recycled. It is expected to enhance schoolchildren's environmental attitude. Particularly, people emphasize ecofriendly awareness and sustainable developments nowadays, schoolchildren are required to possess optimistic environmental attitudes so as to present more positive and optimistic behaviors in their life.

\section{REFERENCE}

[1] Abdollahzadehgan, A., Gohary, M. M., Amini, M. (2013): The Organizational Critical Success Factors for Adopting Cloud Computing in SMEs. - Journal of Information Systems Research and Innovation (JISRI) 4, 67-74.

[2] Alatawi, F. M. H., Dwivedi, Y. K., Williams, M. D., Rana, N. P. (2012): Conceptual Model For Examinig Knowledge Management System (KMS) Adoption in Public Sector Organizations In Saudi Arabia. - tGOV Workshop, 2012, Brunel University, London, UK.

[3] Araghi, Y., Kroesen, M., Molin, E., Wee, B. V. (2014): Do social norms regarding carbon offsetting affect individual preferences towards this policy? Results from a stated choice experiment. - Transportation Research Part D 26: 42-46.

[4] British Airways (2012): Corporate social responsibility report 2012.

[5] Chang, C. C. (2011): Feeling Ambivalent about Going Green: Implications for Green Advertising Processing, - Journal of Advertising 40: 19-31.

[6] Chen, F. Y. (2013): The intention and determining factors for airline passengers' participation in carbon offset schemes. - Journal of Air Transport Management 29: 17-22.

[7] Chen, F. Y., Hsu, P. Y., Lin, T. W. (2011): Air Travelers' Environmental Consciousness: A Preliminary Investigation in Taiwan. - International Journal of Business and Management 6: 78-86.

[8] Davison, L., Littleford, C., Ryley, T. (2014): Air travel attitudes and behaviours: The development of environment-based segments. - Journal of Air Transport Management 36: 13-22.

[9] Enfield, M., Mathew, E. (2012): How a picture book brought the concept of change in position to life. - Science and Children 50: 46-49.

[10] Hadzigeorgiou, Y., Prevezanou, B., Kabouropoulou, M., Konsolas, M. (2011): Teaching about the importance of trees: a study with young children. - Environmental Education Research 17: 519-536.

[11] Joe, C., Yoong, P., Patel, K. (2013): Knowledge loss when older experts leave knowledge-intensive organizations. - Journal of Knowledge Management 17: 913-927.

[12] Kim, Y., Yun, S., Lee, J. (2014): Can Companies Induce Sustainable Consumption? The Impact of Knowledge and Social Embeddedness on Airline Sustainability Programs in the U.S. - Sustainability 6: 3338-3356.

[13] Ko, D. G., Dennis, A. R. (2011): Profiting from knowledge management: The impact of time and experience. - Information Systems Research 22: 134-152.

[14] Lee, K. (2011a): The Green Purchase Behavior of Hong Kong Young Consumers: The Role of Peer Influence, Local Environmental Involvement, and Concrete Environmental Knowledge. - Journal of International Consumer Marketing 23: 21-44.

[15] Lee, K. (2011b): The role of media exposure, social exposure and biospheric value 
orientation in the environmental attitude-intention-behavior model in adolescents. Journal of Environmental Psychology 31: 301-308.

[16] Lian, J. W., Yen, D. C., Wang, Y. T. (2014): An exploratory study to understand the critical factors affecting the decision to adopt cloud computing in Taiwan hospital. International Journal of Information Management 34: 28-36.

[17] Lu, J. L., Shon, Z. Y. (2012): Exploring airline passengers' willingness to pay for carbon offsets. - Transportation Research Part D 17: 124-128.

[18] Mantzicopoulos, P., Patrick, H. (2011): Reading picture books and learning science: engage young children with informational text. - Theory into Practice 50: 269-276.

[19] Mitchener, C. P., Jackson, W. M. (2012): Learning from action research about science teacher preparation. - Journal of Science Teacher Education 23: 45-64.

[20] Scheelhaase, J., Grimme, W., Schaefer, M. (2010): The inclusion of aviation into the EU emission trading scheme. - Impacts on competition between European and non-European network airlines. Transportation Research Part D 15, 14-25.

[21] Shabnam, S. (2013): Proposed Model for Predicting Environmental Purchase Behavior of Consumers - European Academic Research 1(4):444-466.

[22] Sultan, N. (2013): Knowledge management in the age of cloud computing and Web 2.0: Experiencing the power of disruptive innovations. - International Journal of Information Management 33(1): 160-165.Consumers. European Academic Research 4, 444-466.

[23] Van Birgelen, M., Semeijn, J., Behrens, P., (2011): Explaining pro-environment consumer behavior in air travel. - Journal of Air Transport Management 17: 125-128.

[24] Van Der Linden, S. (2014): Towards a new model for communicating climate change. In: Cohen, S., Higham, J., Peeters, P., Gössling, S. (eds.) Understanding and governing sustainable tourism mobility: Psychological and behavioural approaches, pp. 243-275, Routledge: Taylor and Francis Group

[25] Vlahakis, G. N., Skordoulis, K., Tampakis, K. (2013): Introduction: Science and Literature. Science \&; Education. -Advance online publication. doi: 10.1007/s11191013-9601-x.

[26] Ziegler, A., Schwarzkopf, J., Hoffmann, V. H. (2012): Stated versus revealed knowledge: Determinants of offsetting $\mathrm{CO} 2$ emissions from fuel consumption in vehicle use. Energy Policy 40: 422-431.

[27] Zsóka, A., Szerényi, Z. M., Széchy, A., Kocsis, T. (2013): Greening due to environmental education? Environmental knowledge, attitudes, consumer behavior and everyday proenvironmental activities of Hungarian high school and university students. - Journal of Cleaner Production 48: 126-138. 